\title{
Dietary patterns and odds of Type 2 diabetes in Beirut, Lebanon: a case-control study
}

Farah Naja ${ }^{1,3}$, Nahla Hwalla ${ }^{1,3}$, Leila Itani ${ }^{1}$, Maya Salem¹, Sami T Azar ${ }^{2}$, Maya Nabhani Zeidan ${ }^{1}$ and Lara Nasreddine $e^{1,3^{*}}$

\begin{abstract}
Background: In Lebanon, Type 2 diabetes (T2D) has a major public health impact through high disease prevalence, significant downstream pathophysiologic effects, and enormous financial liabilities. Diet is an important environmental factor in the development and prevention of T2D. Dietary patterns may exert greater effects on health than individual foods, nutrients, or food groups. The objective of this study is to examine the association between dietary patterns and the odds of T2D among Lebanese adults.

Methods: Fifty-eight recently diagnosed cases of T2D and 116 population-based age, sex, and place of residence matched control participants were interviewed. Data collection included a standard socio-demographic and lifestyle questionnaire. Dietary intake was evaluated by a semi-quantitative 97-item food frequency questionnaire. Anthropometric measurements including weight, height, waist circumference, and percent body fat were also obtained. Dietary patterns were identified by factor analysis. Multivariate logistic regression analysis was used to evaluate the associations of extracted patterns with T2D. Pearson correlations between these patterns and obesity markers, energy, and nutrient intakes were also examined.
\end{abstract}

Results: Four dietary patterns were identified: Refined Grains \& Desserts, Traditional Lebanese, Fast Food and Meat \& Alcohol. While scores of the "Refined Grains \& Desserts" had the highest correlations with energy $(r=0.74)$ and carbohydrates $(r=0.22)$, those of the "Fast Food" had the highest correlation with fat intake $(r=0.34)$. After adjustment for socio-demographic and lifestyle characteristics, scores of the Refined Grains \& Desserts and Fast Food patterns were associated with higher odds of T2D (OR: 3.85, Cl: 1.13-11.23 and OR: 2.80, Cl: 1.14-5.59; respectively) and scores of the Traditional Lebanese pattern were inversely associated with the odds of T2D (OR: 0.46, Cl: 0.22-0.97).

Conclusions: The findings of this study demonstrate direct associations of the Refined Grains \& Desserts and Fast Food patterns with T2D and an inverse association between the Traditional Lebanese pattern and the disease among Lebanese adults. These results may guide the development of nutrition interventions for the prevention and management of T2D among Lebanese adults.

Keywords: Dietary patterns, Lebanon, Type 2 diabetes

\footnotetext{
* Correspondence: In10@aub.edu.lb

${ }^{1}$ Department of Nutrition and Food Sciences, Faculty of Agriculture and

Food Sciences, American University of Beirut, P. O. Box 11-0236, Riad El-Solh,

Beirut 1107-2020, Lebanon

${ }^{3}$ Members of the Public Health and Nutrition (PHAN) Research Group at the

American University of Beirut, P.O.Box 11-0236, Riad El-Solh, Beirut

1107-2020, Lebanon

Full list of author information is available at the end of the article
} 


\section{Introduction}

Type 2 Diabetes (T2D) has reached epidemic proportions in both developed and developing countries and is now recognized as a major global health problem [1-4]. Lebanon, similar to other counties of the Middle East North Africa Region (MENA) region, is witnessing a polarization in disease patterns with under nutrition and its related diseases coexisting with chronic diseases such as T2D and cardiovascular diseases typically associated with developed countries [5]. Even though the prevalence of T2D among adults in Lebanon (15.8\%) [6] appears to be lower than that reported from most other countries in the MENA region including Bahrain (25.5\%), United Arab Emirates (23.3\%) and Saudi Arabia (23.7\%) [5], available data in the country suggested that prevalence rates of the disease are following an alarming trend over time, increasing from $11.6 \%$ in 1999 to $15.8 \%$ in 2004 [6,7]. According to the International Diabetes Federation, the projected prevalence of T2D among adults in Lebanon for year 2020 is $20.4 \%$ [8]. This is corroborated by a recent report suggesting that, worldwide, the greatest relative increase in the number of people with diabetes is expected to occur in countries of the Middle Eastern crescent [9]. This escalating trend in disease prevalence coupled to significant downstream pathophysiologic effects and enormous financial liabilities poses a major public health problem that necessitates the search for mitigating factors and strategies to address them.

Dietary intake is an important modifiable environmental risk factor in the development and prevention of T2D [10]. Although there is convincing evidence that excess consumption of calories and high glycemic index foods that are also low in phytochemical content are associated with an increased risk of T2D [11-14], the evidence regarding the association of other dietary related risk factors with T2D is far less complete [15]. More recently, several nutritional epidemiologic studies have examined the association between dietary patterns rather than single nutrients in relation to the risk of T2D. Dietary patterns may exert greater effects on health than individual foods, nutrients, or food groups [16]. This approach has been used to study obesity, diabetes, cancer, cardiovascular diseases, and all-cause mortality [17-24]. Most of the studies investigating the association of various dietary patterns with the risk of T2D -whether patterns were derived a posteriori (using cluster or factor analyses) or according to hypothesisdriven methods (such as index analysis) - showed that the adoption of a Western and Western-like dietary patterns, characterized by high intakes of processed foods, red meat, and refined grains, were related to a higher risk of glucose intolerance and T2D [17,21-27]. A recent study in Lebanon also showed that adherence to a Western dietary pattern was associated with higher odds of hyperglycemia and metabolic syndrome [28].

Furthermore, a Mediterranean dietary pattern, characterized by high consumption of fruits, vegetables, fish, and olive oil, has also been suggested to be protective against the risk of metabolic abnormalities and T2D [29-32]. In the East Mediterranean region, studies evaluating the association between the different dietary patterns and the risk of T2D are scarce [33,34].

The aim of this study was to examine the association of various dietary patterns with the odds of T2D among Lebanese adults. Findings from this study could inform prevention strategies among Lebanese adults with high risk of T2D.

\section{Materials and methods}

This study was approved by the Institutional Review Board at the American University of Beirut. All participants signed a consent form prior to participation and had the right to withdraw from the study at any time.

\section{Study design}

This is a case control study that investigated the association between dietary patterns and the odds of T2D among Lebanese adults. Eligible cases were patients older than 18 years of age, who were newly diagnosed with T2D (within 6 months of recruitment) and were attending the Private Clinics or the Dietary Department at the American University of Beirut Medical Center between April 2009 and December 2010. Controls were randomly selected from the general population and were matched to cases by age ( \pm 5 years), sex, and area residence. Whenever a case was identified and recruited in the study, a control participant who is within \pm 5 year-age interval of the case was recruited. For example, if a case was 45 years old, the matching control participant ought to be between 40 and 50 years of age. Matching for place of residence was performed, given that, in the Lebanese context, residents of the same of area tend to have comparable socioeconomic status [35]. After a case of T2D was identified in the clinical setting, a matching control was randomly chosen from the same or from the two adjacent residential buildings in which the case resided. In most buildings of Beirut, the names of residents are listed on an interphone list in the building entrance. The field worker will contact a random resident from this list and ask for the availability of a healthy adult who matches the case on age and sex. Should there be more than one adult in the household satisfying the inclusion criteria then only one is chosen. Controls had to be free of diagnosed diabetes. Two controls were selected to match each case. Recruitment of a matching control participant took place within two weeks of the case enrolment in the study. The sample size for this study $(\mathrm{n}=180)$ was calculated using an alpha of 0.05 , 
a power of $80 \%$, and a standard effect ( $\omega$ parameter described by Cohen 1988 [36]) of 0.5, detecting a minimum significant outcome measure (OR) of 2.44 .

\section{Data collection}

In a one to one interview, study participants completed a brief socio-demographic and lifestyle questionnaire and a semi quantitative Food Frequency Questionnaire (FFQ). In addition anthropometric measurements, including weight, height, waist circumference and percent body fat, were obtained. All the interviews were conducted by trained dieticians.

The sociodemographic and lifestyle questionnaire retrieved information regarding the following characteristics: age (continuous in years), sex, income per month ( $\leq 1.5$ million L.L., >1.5 million L.L.; 1500 L.L is equivalent to almost \$1 U.S.), marital status (single including single, divorced, and widowed, and married including currently married or living with a partner), education (less than high school education and greater than high school education), smoking (smokers including current smokers, non smokers including non-smokers and past smokers), physical activity (Low physical activity including light activities such as housework and casual walking and moderate to high physical activity including all other types of exercise such as biking, dancing, running, and aerobics), family history of T2D (a positive family history of T2D was indicated if the mother, father or both were diagnosed with the disease), frequency of breakfast consumption per week (continuous), and number of meals per day (continuous).

\section{Anthropometric measurements}

Anthropometric measurements were obtained using standardized techniques and calibrated equipments. Participants were weighed to the nearest $0.1 \mathrm{~kg}$ in light indoor clothing and with bare feet or stockings. Using a stadiometer, height was measured without shoes and recorded to the nearest $0.5 \mathrm{~cm}$. Body mass index (BMI) was calculated as the ratio of weight (kilograms) to square of height (meters squared). Waist circumference was measured using a plastic measuring tape, to the nearest $0.5 \mathrm{~cm}$, at the midpoint between the bottom of the rib cage and above the top of the iliac crest during minimal respiration. Body fat was measured by the leg to leg bioelectric impedance (BIA) system (Tanita Body Fat Analyzer, TBF 105, Tanita Corporation of America, Inc., Arlington Heights, IL). Prior to BIA testing, participants were required to adhere to standard BIA testing guidelines, and bioelectrical impedance was measured in participants standing erect with bare feet on the analyzer's footpads. Fat Free Mass and percent body fat from BIA were calculated using the prediction equation supplied by the manufacturer. The validity of this method of body fat assessment was tested against underwater weighing and was shown to accurately assess body fat in men and women $[37,38]$.

\section{Dietary intake assessment}

Dietary intake of participants was assessed by a 97-item semi quantitative FFQ adapted from an instrument used in the total diet study of adult urban population in Beirut, Lebanon [39]. Further details about the development of the original questionnaire were described elsewhere [39]. The FFQ referred to food intake one year prior to diagnosis of T2D for cases and during the previous 12 months for controls. The questionnaire assessed the intake of commonly consumed food items grouped into 23 categories namely bread and cereals, grains and pasta, milk and dairy, fruits, juices, vegetables, potatoes, legumes, meat, poultry, fish, organ meat, eggs, fats and oils, caffeinated beverages, sweets and desserts, ice-cream, puddings, sugar derivatives, beverages, mixed dishes, fast food, and alcohol. Food items under each category were chosen to provide comprehensive representation of the Lebanese diet. Where possible, foods were separated into low fat and whole fat groups. The reference portions of the 2 dimensional food portion visual (Millen and Morgan, Nutrition Consulting Enterprises, Framingham, Massachusetts, United States) were used. Participants were asked to recall how often, on average, they consumed the specified portion size of every food item per day, per week, per month or never. Portion sizes, consumed from each food item, were then converted to daily portion intake. Daily energy and nutrient intakes were computed by multiplying the daily frequency of intake by the nutrient content of the specified portion size; using the food composition tables provided by N4 software (provided by $\mathrm{N}$-squared Computing Nutritionist IV. Silverton (Oregon): N-squared Computing 1993) and using the food composition table of Middle Eastern foods for local and traditional dishes [40].

\section{Dietary patterns derivation}

For the purpose of determination of dietary patterns, food items were grouped into twenty five food groups based on nutrient profile and culinary usage (Additional file 1: Appendix A). We have opted to include alcohol intake as a food group in the factor analysis rather than as a covariate in the association between patterns and T2D to allow for comparability with our previous studies assessing dietary patterns and diseases in Lebanon, where alcohol intake was also part of the factor analysis in dietary patterns derivation $[28,41]$. The total consumption for each food group was determined by summing the daily intake of servings from each item in this group. Food groups' intakes were not adjusted for energy. Prior to running the factor analysis procedure, the correlation matrix between the twenty five food 
groups was visually and statistically examined to justify undertaking factor analysis. The chi square for Bartlett test of sphericity was significant at a p-value less than 0.05 and Kaiser-Meyer-Olkin test was greater than 0.6 [42]. The exploratory principal component factor analysis (PCFA) was implemented to identify dietary patterns using intake of the twenty five food groups. The number of factors retained was based on three criteria 1) the Kaiser criterion (eigenvalues $>1$ ), 2) inflection point of the scree plot, and 3) the interpretability of factors $[43,44]$. The derived dietary patterns were labeled based on food groups having a rotated factor loading greater than 0.4 . Factor scores were calculated by multiple regression approach whereby independent variables in the regression equation are the standardized observed values of the items in the estimated patterns. These predictor variables are weighted by regression coefficients, which are obtained by multiplying the inverse of the observed variable correlation matrix by the matrix of factor loadings. The factor scores are the dependent variables in the regression equation [45]. Each individual received a factor score for each dietary pattern. Further details about the derivation of dietary patterns are described elsewhere [28].

\section{Descriptive and other statistical analyses}

Frequencies, means and standard deviations (SD) were used to describe various sociodemographic, lifestyle, and anthropometric characteristics of cases and controls. Independent student t-test and Chi-square test were used to compare continuous and categorical variables respectively. Pearson's correlation coefficients were used to examine the association between the derived dietary patterns and obesity markers (including BMI, waist circumference and percent body fat), energy, and energy adjusted nutrient intakes. Energy adjustment was carried out using the regression residual method [46]. The association between dietary patterns scores and odds of T2D was assessed using multivariate logistic regression models where the score of each dietary pattern was entered simultaneously as an independent variable in addition to other covariates. Covariates used in the logistic regression modeling included: energy, obesity markers (including BMI, waist circumference, percent body fat), age, sex, income, education, marital status, smoking, family history of T2D, physical activity, number of meals per day, and frequency of breakfast consumption. All analyses were two tailed and a $p$-value $<0.05$ was considered statistically significant. The Statistical Package for the Social Sciences was used for all computations (SPSS) (version 19.0, SPSS Inc., Chicago, Illinois, USA).

\section{Results}

During the study period, 65 newly diagnosed cases of T2D were identified, and 58 agreed to participate in the study (response rate: $89 \%$ ). Out of 139 control participants approached, 116 were enrolled in the study (response rate: $82 \%)$. The main reasons for declining participation were "lack of time" and "no interest".

Table 1 presents the means and proportions of sociodemographic, lifestyle, and anthropometric characteristics of the study population. Mean age of the total study population was $56.18 \pm 10.93$ years (range: $40-79$ years). Cases and controls were comparable across age, sex, income, marital status, education, and smoking. There were significant differences between cases and controls with regard to family history of T2D, physical activity, BMI, waist circumference, and percent body fat. Compared to controls, a higher proportion of cases reported a family history of T2D (58.6\% vs. $13.8 \%$ ). Cases who reported engaging in moderate to high physical activity levels were fewer than the controls (19.0\% vs. $51.7 \%)$. Compared to controls, cases had a significantly higher mean BMI (30.79 \pm 5.51 vs. $26.81 \pm 4.48 \mathrm{Kg} / \mathrm{m} 2)$, higher percent body fat ( $33.43 \pm 8.76$ vs. $28.88 \pm 7.12)$, and a larger waist circumference $(106.53 \pm 12.01$ vs. $95.92 \pm 12.00 \mathrm{~cm})$.

Factor analysis revealed four dietary patterns: Refined Grains \& Desserts, Traditional Lebanese, Fast Food and Meat \& Alcohol which explained 13.68\%, 10.8\%, 9.13\%, and $8.67 \%$ of the dietary intake variance respectively (Table 2). The factor loading matrix derived from PCFA is shown in Table 2. The Refined Grains \& Desserts pattern featured high consumption of pasta, desserts, fried fish, pizzas and pies, in addition to breakfast cereals and white bread. The second pattern, Traditional Lebanese, was mostly associated with consumption of olives and olive oil, fruits and vegetables, low fat milk and milk products, traditional Lebanese dishes, whole wheat bread, Arabic sweets, and "Shawarma" \& "Falafel". The Fast Food pattern was characterized by high intakes of French fries, added fat, fast food sandwiches, mixed nuts, and full fat milk and milk products. The fourth pattern Meat \& Alcohol loaded mostly on eggs, alcohol, red meat, juices and carbonated beverages, chicken, and fish (not fried). Eggs is often cited with meats as one food group (in most of the food guide pyramids, MyPlate, MyCedar, etc.), hence this pattern's name "Meat \& Alcohol" encompasses eggs as well.

Table 3 shows the associations between the factor scores of the four dietary patterns with obesity markers, energy, and energy adjusted nutrient intakes as assessed by Pearson correlation coefficients. Nutrients which have been previously reported to be associated with T2D were included in this analysis. While the Refined Grains \& Desserts, the Fast Food, and the Meat \& Alcohol patterns were directly associated with BMI and waist circumference, inverse associations were noted between the Traditional Lebanese pattern and these obesity markers. Percent body fat was only directly associated with the Fast Food pattern $(r=0.249)$. The scores of the Refined Grains \& Desserts, 
Table 1 Socio-demographic and anthropometric characteristics of the study population ${ }^{a}$

\begin{tabular}{|c|c|c|c|c|}
\hline & Total $(n=174)$ & Cases $(\mathbf{n}=\mathbf{5 8})$ & Controls $(n=116)$ & Significance $^{b}$ \\
\hline Age (years) (Mean \pm SD) & $56.18 \pm 10.93$ & $56.55 \pm 11.20$ & $55.99 \pm 10.84$ & P-value $>0.05$ \\
\hline Sex & & & & $X^{2}=0.00$, P-value $>0.05$ \\
\hline Males & 105(60.3) & $35(60.3)$ & $70(60.3)$ & \\
\hline Females & $69(39.7)$ & 23(39.7) & $46(39.7)$ & \\
\hline Income per month ${ }^{c}$ & & & & $X^{2}=1.521$, P-value $>0.05$ \\
\hline$\leq 1.5$ million LL & $44(25.3)$ & 18(31.0) & $26(22.4)$ & \\
\hline$>1.5$ million LL & 130(74.7) & $40(69.0)$ & $90(77.6)$ & \\
\hline Marital status & & & & $X^{2}=1.04$, P-value $>0.05$ \\
\hline Single & $28(16.1)$ & $7(12.1)$ & $21(18.1)$ & \\
\hline Married & 146(83.9) & $51(87.9)$ & 95(81.9) & \\
\hline Education & & & & $X^{2}=3.85$, P-value $>0.05$ \\
\hline$<$ High school & $31(17.8)$ & 15(25.9) & 16(13.8) & \\
\hline$\geq$ High school & 143(82.2) & $43(74.1)$ & $100(86.2)$ & \\
\hline Family history of diabetes & & & & $X^{2}=37.94$, P-value $<0.001$ \\
\hline None & $124(71.3 \%)$ & $24(41.4 \%)$ & $100(86.2 \%)$ & \\
\hline Yes (mother, father or both) & $50(28.7 \%)$ & $34(58.6 \%)$ & $16(13.8 \%)$ & \\
\hline Smoking & & & & $X^{2}=0.12$, P-value $>0.05$ \\
\hline Non smoker & $120(69.0)$ & $41(70.7)$ & $79(68.1)$ & \\
\hline Smoker $^{d}$ & $54(31.0)$ & 17(29.3) & $37(31.9)$ & \\
\hline Physical activity level & & & & $X^{2}=17.18$, P-value $<0.01$ \\
\hline Low physical activity & 103(59.2) & $47(81.0)$ & $56(48.3)$ & \\
\hline Moderate to high physical activity & $71(40.8)$ & 11(19.0) & $60(51.7)$ & \\
\hline Breakfast per week (Mean \pm SD) & $5.83 \pm 2.12$ & $5.72 \pm 1.94$ & $5.90 \pm 2.22$ & P-value $>0.05$ \\
\hline Meals per day (Mean \pm SD) & & & & $X^{2}=0.27, P$-value $>0.05$ \\
\hline 1-2 meals per day & $38(21.8)$ & $14(24.1)$ & $24(20.7)$ & \\
\hline$\geq 3$ meals per day & 136(78.2) & 44(75.9) & $92(79.3)$ & \\
\hline Percent Body fat (\%) (Mean \pm SD) & $30.40 \pm 7.98$ & $33.43 \pm 8.76$ & $28.88 \pm 7.12$ & P-value $<0.001$ \\
\hline $\mathrm{BMI}\left(\mathrm{Kg} / \mathrm{m}^{2}\right)($ Mean $\pm \mathrm{SD})$ & $28.14 \pm 5.19$ & $30.79 \pm 5.51$ & $26.81 \pm 4.48$ & P-value $<0.001$ \\
\hline obese $(\mathrm{BMI}>=30)^{\mathrm{e}}$ & $61(35.1)$ & $32(55.2)$ & $29(25.0)$ & $X^{2}=15.46$, P-value $<0.001$ \\
\hline Waist circumference $(\mathrm{cm})($ Mean \pm SD) & $99.45 \pm 12.98$ & $106.53 \pm 12.01$ & $95.92 \pm 12.00$ & P-value $<0.001$ \\
\hline Elevated waist circumference ${ }^{f}$ & 145(83.3) & $57(98.3)$ & $88(75.9)$ & $X^{2}=13.99$, P-value $<0.001$ \\
\hline
\end{tabular}

${ }^{a}$ Categorical variables are expressed as $\mathrm{n}(\%)$; continuous variables are expressed as Mean \pm SD.

${ }^{b}$ Significance is derived from independent t-test for continuous variables and Chi square test for categorical variables.

'Income is expressed in terms of Lebanese Liras L.L (1500 L.L is almost equivalent to \$1 U.S.).

${ }^{d}$ Smokers were defined as current smokers while non-smokers included non-smokers and past smokers.

eObesity is defined as $\mathrm{BMI} \geq 30 \mathrm{Kg} / \mathrm{m}^{2}$.

f Elevated waist circumference is defined by a circumference $\geq 94 \mathrm{~cm}$ for males and $\geq 80 \mathrm{~cm}$ for females according to the International Diabetes Foundation (IDF).

the Traditional Lebanese, the Meat \& Alcohol patterns were directly correlated with energy, with those of the Refined Grains \& Desserts pattern having the highest correlation $(r=0.741)$. In addition, the scores of the Refined Grains \& Desserts pattern were directly correlated with total carbohydrates $(r=0.221)$ and sucrose $(r=0.161)$. The Traditional Lebanese pattern scores correlated directly with monounsaturated fat $(r=0.350)$ and dietary fiber $(r=0.411)$ intakes. The Fast Food pattern had the highest correlation with fat intake $(r=0.344)$. Compared to other patterns, the
Meat \& Alcohol pattern had the highest correlation with protein intake $(\mathrm{r}=0.358)$.

Table 4 showed the association between the identified dietary patterns scores with the odds of T2D. In the final multivariate logistic regression model (adjusted for energy, sociodemographic and lifestyle characteristics, BMI, waist circumference, and percent body fat), a unit increase in the scores of the Refined Grains \& Desserts pattern was associated with more than 3 folds increase in the odds of T2D (OR: 3.85, CI: 1.31-11.23). Similarly, 
Table 2 Factor loading matrix for the four identified dietary patterns in the study population ${ }^{a, b}$

\begin{tabular}{|c|c|c|c|c|}
\hline \multirow[t]{2}{*}{ Food group } & \multicolumn{4}{|c|}{ Patterns } \\
\hline & $\begin{array}{c}\text { Refined } \\
\text { grains \& desserts }\end{array}$ & $\begin{array}{l}\text { Traditional } \\
\text { Lebanese }\end{array}$ & $\begin{array}{l}\text { Fast } \\
\text { food }\end{array}$ & $\begin{array}{l}\text { Meat \& } \\
\text { alcohol }\end{array}$ \\
\hline Pasta & 0.75 & & & \\
\hline Desserts & 0.62 & & 0.25 & \\
\hline Fried fish & 0.58 & & & \\
\hline Pizza and pies & 0.56 & 0.21 & & \\
\hline Breakfast cereals & 0.55 & & & \\
\hline White bread & 0.53 & & 0.25 & \\
\hline Olives and olive oil & & 0.67 & & \\
\hline Fruits & & 0.60 & 0.25 & 0.35 \\
\hline Vegetables & & 0.59 & & 0.25 \\
\hline $\begin{array}{l}\text { Low fat milk and } \\
\text { milk products }\end{array}$ & & 0.50 & & \\
\hline $\begin{array}{l}\text { Traditional Lebanese } \\
\text { dishes }\end{array}$ & & 0.42 & & \\
\hline Whole wheat bread & & 0.37 & & \\
\hline Arabic sweets & 0.28 & 0.37 & & \\
\hline $\begin{array}{l}\text { Shawarma and } \\
\text { Falafel }\end{array}$ & & 0.29 & & \\
\hline French Fries & & & 0.60 & 0.22 \\
\hline Added fat & & & 0.45 & \\
\hline Fast food sandwiches & & & 0.57 & \\
\hline Mixed nuts & 0.21 & 0.29 & 0.54 & 0.24 \\
\hline $\begin{array}{l}\text { Full fat milk and milk } \\
\text { products }\end{array}$ & 0.24 & & 0.41 & 0.27 \\
\hline Eggs & & & & 0.61 \\
\hline Alcohol & & & & 0.54 \\
\hline Red meat & & & & 0.54 \\
\hline $\begin{array}{l}\text { Sweetened juices and } \\
\text { carbonated beverages }\end{array}$ & & & 0.22 & 0.33 \\
\hline Chicken & & & & 0.42 \\
\hline Fish (not fried) & & & & 0.23 \\
\hline $\begin{array}{l}\text { Percent variance } \\
\text { explained by each } \\
\text { pattern }\end{array}$ & 13.68 & 10.80 & 9.13 & 8.67 \\
\hline
\end{tabular}

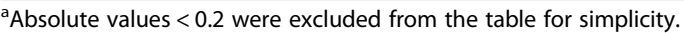
${ }^{\mathrm{b}}$ Absolute values $\geq 0.3$ are bolded.

scores of the Fast Food pattern were associated with higher odds of T2D (OR: 2.80, CI: 1.41-5.59). The odds of T2D were lower with increasing scores of the Traditional Lebanese pattern (OR: 0.46, CI: 0.22-0.97). No significant association was noted between the scores of the Meat \& Alcohol dietary pattern and the odds of T2D.

\section{Discussion}

This case control study aimed at evaluating the association between dietary patterns and the odds of T2D in a sample of 58 recently diagnosed cases with the disease and 116 matched controls residing in Beirut, the capital of Lebanon. Studying the association between dietary patterns and T2D overcomes the inconsistent findings of single nutrient analysis in evaluating diet-disease associations, takes into consideration the synergistic effects of nutrients, and produces culture specific recommendations. Furthermore, behavior change could be better achieved when discussed in terms of patterns, rather than nutrients or specific foods, because it gives food context, which in turn may facilitate the development of public health recommendations [16]. Our results revealed four major dietary patterns in this study population: Refined Grains \& Desserts, Traditional Lebanese, Fast Food and Meat \& Alcohol patterns which together explained $42.28 \%$ of the total variance in the dietary intake. The percentage of variance explained by the first four dietary patterns identified is similar in magnitude to what has been reported in others studies $[47,48]$. It should be noted, however, the variance explained by all factors is a function of the number of factors researchers choose to retain [49]. Both the Refined Grains \& Desserts and the Fast Food patterns were associated with higher odds of T2D, while the Traditional Lebanese was inversely associated with the odds of the diseases. No association was observed between the Meat \& Alcohol pattern with the odds of T2D.

Previous studies have reported on the association between dietary patterns and the risk of T2D [21-24,50]. Overall, their results featured two main dietary patterns, the Western and Prudent. The Western pattern, characterized by a high consumption of red meat, eggs, refined grains, desserts, French fries, and high fat dairy products, was associated with higher plasma insulin [47,51], Cpeptide levels [52], and overall risk of T2D [19,21,47,51]. A recent cohort study showed that adherence to a Western pattern characterized by high intakes of desserts, meats, and refined grains during adolescence was associated with $29 \%$ increase in the risk of T2D in middle aged women [53]. The Prudent pattern contained high amounts of fruits, vegetables, legumes, fish, poultry, and low fat dairy products and was not always reported as associated with reduced risk of disease $[19,21,23,25]$. Hence, the association between the prudent pattern and the risk of T2D was less evident than that of the Western pattern with the risk of disease. Data describing the association between dietary patterns and T2D in the MENA region are scarce and limited to countries with particular patterns that are country and culture specific [33,34]. In the present study, the Refined Grains \& Desserts and the Fast Food patterns were the two patterns shown to have a direct association with the odds of T2D. Both of these patterns shared important features with the Western pattern previously described in the literature and shown to directly influence the risk of T2D [17,21-27]. The Refined Grains \& Desserts pattern, found in this study, 
Table 3 Pearson's correlation coefficients between pattern scores and anthropometric measurements, total energy and energy adjusted nutrient intakes ${ }^{a}$

\begin{tabular}{lllll}
\hline & Refined grains \& desserts & Traditional Lebanese & Fast food & Meat \& alcohol \\
\hline BMI (Kg/m ${ }^{2}$ ) & $0.173^{*}$ & $-0.236^{* *}$ & $0.223^{* *}$ & $0.159^{*}$ \\
Waist circumference(cm) & $0.233^{*}$ & $-0.262^{* *}$ & $0.225^{* *}$ & $0.237^{* *}$ \\
Percent body fat(\%) & 0.128 & -0.024 & $0.249^{* *}$ & -0.070 \\
Energy ${ }^{\text {(Kcal) }}$ & $0.741^{* *}$ & 0.095 & $0.428^{* *}$ & $0.247^{* *}$ \\
Protein ( g) & $-0.164^{*}$ & -0.094 & 0.051 & $0.358^{* *}$ \\
Fat (g) & $-0.099^{*}$ & $0.196^{*}$ & $0.344^{* *}$ & -0.135 \\
Saturated fatty acids(g) & 0.010 & 0.106 & 0.082 & 0.006 \\
Mono unsaturated fatty acids(g) & -0.090 & $0.350^{* *}$ & $0.232^{* *}$ & -0.060 \\
Polyunsaturated fatty acids(g) & -0.124 & 0.009 & $0.203^{*}$ & -0.051 \\
a-Linolenic acid(g) & -0.048 & -0.027 & 0.142 & $0.223^{* *}$ \\
Linoleic acid(g) & -0.120 & -0.056 & $0.243^{* *}$ & $-0.315^{* *}$ \\
Cholesterol(mg) & 0.095 & -0.129 & -0.074 & 0.114 \\
Carbohydrates(g) & $0.221^{* *}$ & -0.050 & $0.009^{*}$ & 0.065 \\
Dietary fibers(g) & 0.143 & $0.411^{* *}$ & 0.002 & -0.148 \\
Sucrose(g) & $0.161^{*}$ & 0.099 & 0.005 & 0.083 \\
\hline
\end{tabular}

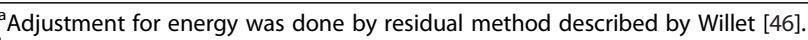

${ }^{\mathrm{b}}$ Absolute values are indicated for the correlation of dietary pattern scores with total energy intake.

* Correlation is significant at $p<0.05$.

${ }^{*}$ Correlation is significant at $p<0.01$.

was characterized by high intake of pasta, desserts, pies, and pizzas, in addition to breakfast cereals and white bread and was directly correlated with energy and carbohydrates intake. The Fast Food pattern was characterized by high intake of chips and fries, fast food sandwiches, full fat milk and milk products, and added fats, and was correlated mainly with energy and fat intake. There are a few mechanisms by which adherence to these patterns may increase the risk of T2D. Many of the foods and food groups loading high on these patterns possess a high glycemic index as well as high glycemic load. Such foods have been repeatedly reported to have a direct association with T2D [54-61]. Foods with a high glycemic load trigger higher postprandial insulin levels, which may lead to an accelerated age related decline in insulin secretion and ultimately the onset of T2D [13]. Furthermore, high consumption of sugar has been independently associated with the odds of T2D $[62,63]$. In line with the findings of this study were the results of the National Nutrition Survey conducted in Lebanon in 2009, which indicated an association between a Western dietary pattern and increased odds of obesity [41], and the metabolic syndrome in Lebanon, conditions postulated to increase the risk of T2D [28].

The Traditional Lebanese pattern identified in this study was inversely associated with the odds of T2D. Although Mediterranean diets could be different from one country to another in the Mediterranean basin [64], the Traditional Lebanese pattern encompasses many features of the generally known Mediterranean diet. These

Table 4 Odds ratios and 95\% confidence intervals for the association between dietary patterns and the odds of T2D in the study population

\begin{tabular}{|c|c|c|c|c|c|c|c|c|}
\hline & \multicolumn{2}{|c|}{ Refined grains \& desserts } & \multicolumn{2}{|c|}{ Traditional Lebanese } & \multicolumn{2}{|c|}{ Fast food } & \multicolumn{2}{|c|}{ Meat \& alcohol } \\
\hline & OR & $95 \% \mathrm{Cl}$ & OR & $95 \% \mathrm{Cl}$ & OR & $95 \% \mathrm{Cl}$ & OR & $95 \% \mathrm{Cl}$ \\
\hline Model $1^{*}$ & 2.94 & $1.26-6.84$ & 0.53 & $0.31-0.91$ & 2.09 & $1.28-3.41$ & 1.05 & $0.69-1.59$ \\
\hline Model $2^{* *}$ & 3.22 & $1.17-8.84$ & 0.60 & $0.33-1.08$ & 2.32 & $1.32-4.06$ & 1.19 & $0.71-1.98$ \\
\hline Model $3^{* * *}$ & 3.85 & $1.31-11.23$ & 0.46 & $0.22-0.97$ & 2.80 & $1.41-5.59$ & 1.43 & $0.83-2.46$ \\
\hline
\end{tabular}

"Model 1 is adjusted for age (in years), sex (male, female), waist circumference (in $\mathrm{cm}$ ), body fat (percentage), BMI (in Kg/m²), and energy (Calories).

${ }^{* *}$ Model 2 is adjusted for variables in model 1 as well as income per month ( $\leq 1.5$ million L.L., >1.5 million L.L.; 1500 L.L is almost equivalent to \$1 U.S.), smoking (smokers including current smokers, non smokers including non-smokers and past smokers), family history of T2D (yes vs. no), education (less than high school education and greater than high school education), marital status (single including single, divorced, and widowed, and married including currently married or living with a partner).

${ }^{* * *}$ Model 3 is adjusted for variables in model 1 and model 2 as well as physical activity (low vs. middle to high levels), meals per day ( $1-2$ vs. $\geq 3$ meals per day), breakfast (frequency per week). 
features include consumption of fruits, vegetables, olives and olive oil, and whole bread [65]. Adherence to a Mediterranean diet has been repeatedly shown to exert a beneficial role regarding the development and progression of T2D [29-32,66]. Additionally, individual food groups and components of the diet, such as monounsaturated fatty acids, fruits, vegetables, and whole grain cereals may protect against the development of diabetes, possibly through the amelioration of insulin sensitivity and their anti-inflammatory actions [67]. A recent study among adults in rural Lebanon indicated that adherence to a Mediterranean diet, as assessed using the widely used Mediterranean diet score (MDS), is negatively associated with two of T2D known risk factors: obesity and visceral adiposity [68].

Our results indicated that the Meat \& Alcohol pattern did not show an association with the odds of T2D. This pattern included food groups that were shown to be associated with varying odds of T2D. For instance, frequent consumption of meat, in particular red meat, has been reported to increase the risk of diabetes in prospective studies $[21,69,70]$. Furthermore, recent evidence, though inconclusive, suggested that increased consumption of eggs may raise blood cholesterol concentrations and thereby increase the risk of T2D by impairing islet cell function [71-73]. On the other hand consumption of fish was shown to decrease the risk of the disease [50]. N-3 fatty acids (including $\alpha$-Linolenic acid found to be positively correlated with the scores of this pattern) have been suggested to have beneficial effects on health outcomes such as reduction in concentrations of inflammatory markers and improvement of insulin sensitivity [74]. This inverse association between fish intake and the risk of T2D was challenged by a recent meta-analysis by Patel et al., which showed that lean fish, total fish, and shellfish intakes were not associated with incident diabetes but that fatty fish intake may be weakly inversely associated [75]. Moderate alcohol consumption (1-3 drinks per day) has been shown to be associated with lower risk of diabetes [76] and lower levels of pro inflammatory markers [77]. Hence the negative effects of meat and egg consumption on the odds of T2D could have been neutralized by the protective effect fish and moderate alcohol consumption might have had on the odds of the disease.

A few limitations should be considered when interpreting the findings of this study. The recall of past diet rises concerns regarding the possibility of recall bias among cases if their diet changed as a result of their diagnosis, or because they experienced symptoms as a result of the presence of subclinical disease before diagnosis. It is also possible that the dietary intake interview reflected changes due to medical advice. To minimize this recall bias, cases were constantly reminded to report on their dietary intake before diagnosis with T2D. Another limitation stems from the use of factor analysis in the derivation of the dietary patterns. This method involves many subjective decisions in selecting and grouping foods for analysis from the questionnaire, in determining the number of factors to retain, in choosing the method of rotation of the initial factors and in labeling dietary patterns according to their factor loadings [78]. To address the issue of subjectivity using factor analysis, the food groupings used in this study were similar to those reported by others in the region $[28,33,34,41]$ and the selection of the factor solution was done after evaluating the scree plots and eigenvalues. It remains important to note that the food frequency questionnaire used in this study was not validated in our study population. The fact that the food frequency questionnaire was administered by a trained dietitian and not self-completed offers many advantages in that it does not require a literate population and results in consistent interpretations and higher response and completion rates, each of which may enhance the validity of the data $[78,79]$. Furthermore, any nondifferential measurement error of the diet is likely to have attenuated the associations that we have observed. Finally, although significant associations were found between the Refined Grains \& Desserts, the Traditional Lebanese and the Fast Food patterns with the odds of T2D, the small sample size of this study might have lead to insufficient power to detect an association between the Meat \& Alcohol pattern and the disease.

\section{Conclusion}

This study provides insight to the association between dietary patterns and T2D, particularly among Lebanese adults, a currently understudied population. Our findings suggested that Refined Grains \& Desserts and Fast Food dietary patterns were associated with increased odds of T2D while a Traditional Lebanese pattern was indirectly associated with the odds of the disease. Thus our results allow for evidence-based recommendations to limit the consumption of refined grains products, desserts, fast food sandwiches, French fries, and added fats as well as encouraging the consumption of a Traditional pattern based on fruits and vegetables. These recommendations lay grounds for planning intervention strategies that are culture based and in line with local dietary habits. The findings of this study are important not only in Lebanon but also in other countries of the Middle East region where such patterns are predominantly available. 


\section{Additional file}

Additional file 1: Appendix A. Food groups used in the analysis of the dietary patterns.

\section{Abbreviations}

T2D: Type 2 Diabetes OR, Odds Ratio; Cl: Confidence Interval; MENA: Middle East North Africa; FFQ: Food Frequency Questionnaire; BMI: Body Mass Index; BIA: Leg to leg bioelectric impedance; N4: N-squared Computing Nutritionist IV; PCFA: Principal component factor analysis; SD: Standard Deviation; SPSS: Statistical Package for the Social Sciences; r: Correlation coefficient.

\section{Competing interests}

The authors declare that they have no competing interests.

\section{Authors' contributions}

$\mathrm{FN}$, as the principal investigator, was responsible for the concept and design of the study. NH supervised data collection and analysis. LI was responsible for the statistical evaluation of data. MS undertook the dietary assessment of study participants. SA participated in the statistical analysis and data interpretation. MNZ participated in the design of the study and supervision. LN played a central role in integrating the dietary and anthropometric results and acted as lead reviewer. All authors participated in the preparation of, and have approved the final version of the manuscript.

\section{Acknowledgements}

This study was supported by a grant from the American University of Beirut Research Board.

\section{Author details}

${ }^{1}$ Department of Nutrition and Food Sciences, Faculty of Agriculture and Food Sciences, American University of Beirut, P. O. Box 11-0236, Riad El-Solh, Beirut 1107-2020, Lebanon. ${ }^{2}$ Department of Internal Medicine, American University of Beirut, P.O.Box 11-0236, Riad El-Solh, Beirut 1107-2020, Lebanon. ${ }^{3}$ Members of the Public Health and Nutrition (PHAN) Research Group at the American University of Beirut, P.O.Box 11-0236, Riad El-Solh Beirut 1107-2020, Lebanon.

Received: 22 May 2012 Accepted: 4 December 2012 Published: 27 December 2012

\section{References}

1. Boyle JP, Honeycutt AA, Narayan KM, Hoerger TJ, Geiss LS, Chen H, Thompson TJ: Projection of diabetes burden through 2050: impact of changing demography and disease prevalence in the U.S. Diabetes Care 2001, 24(11):1936-1940.

2. International Diabetes Federation ATLAS: 2010. http://www.idf.org/ diabetesatlas/.

3. Sicree R, Shaw J: Type 2 diabetes: An epidemic or not, and why it is happening. Diabetes Metabolic Syndrome Clin Res Rev 2007, 1(2):75-81.

4. Show JE, Sicree RA, Zimmet PZ: Global estimates of the prevalence of diabetes for 2010 and 2030. Diabetes Res Clin Pract 2010, 87(3):4-14

5. Sibai A, Nasreddine L, Mokdad AH, Adra N, Tabet M, Hwalla N: Nutrition transition and cardiovascular disease risk factors in Middle East and North Africa countries: reviewing the evidence. Ann Nutr Metab 2010, 57(3-4):193-203.

6. Hirbli Kl, Jambeine MA, Slim HB, Barakat WM, Habis RJ, Francis ZM: Prevalence of diabetes in greater Beirut. Diabetes Care 2005, 28(5):1262

7. Tohme RA, Jurjus AR, Estephan A: The prevalence of hypertension and its association with other cardiovascular disease risk factors in a representative sample of the Lebanese population. J Hum Hypertens 2005 19(11):861-868.

8. International Diabetes Federation ATLAS. 5th edition. 2012 http://www.idf.org/ diabetesatlas/5e/the-global-burden.

9. Wild S, Roglic G, Green A, Sicree R, King H: Global prevalence of diabetes: estimates for the year 2000 and projections for 2030. Diabetes Care 2004, 27:1047-1053.

10. Alberti KG, Zimmet $P$, Shaw J: International Diabetes Federation: a consensus on Type 2 diabetes prevention. Diabet Med 2007, 24(5):451-463.
11. Hu EA, Pan A, Malik V, Sun Q: White rice consumption and risk of type 2 diabetes: meta-analysis and systematic review. BMJ 2012, 344:e1454.

12. Castañeda-González LM, Bacardí Gascón M, Jiménez Cruz A: Effects of low carbohydrate diets on weight and glycemic control among type 2 diabetes individuals: a systemic review of RCT greater than 12 weeks. Nutr Hosp 2011, 26(6):1270-1276.

13. Riccardi G, Rivellese AA, Giacco R: Role of glycemic index and glycemic load in the healthy state, in prediabetes, and in diabetes. Am J Clin Nutr 2008, 87(1):269S-274S. Review.

14. Jones JL, Fernandez ML, McIntosh MS, Najm W, Calle MC, Kalynych C, Vukich C, Barona J, Ackermann D, Kim JE, Kumar V, Lott M, Volek JS, Lerman $\mathrm{RH}$ : A Mediterranean-style low-glycemic-load diet improves variables of metabolic syndrome in women, and addition of a phytochemical-rich medical food enhances benefits on lipoprotein metabolism. J Clin Lipidol 2011, 5(3):188-196. Epub 2011 Mar 11. PubMed PMID: 21600524.

15. Salas-Salvadó J, Martinez-González MÁ, Bulló M, Ros E: The role of diet in the prevention of type 2 diabetes. Nutr Metab Cardiovasc Dis 2011 21(Suppl 2):B32-B48

16. Hu FB: Dietary pattern analysis a new direction in nutrition epidemiology. Curr Opin Lipidol 2002, 13(1):3-9.

17. Schulze MB, Hoffmann K, Manson JE, Willett WC, Meigs JB, Weikert C, Heidemann C, Colditz GA, Hu FB: Dietary pattern, inflammation, and incidence of type 2 diabetes in women. Am J Clin Nutr 2005a, 82(3):675-684. quiz 714-5.

18. Schulze MB, Hu FB: Primary prevention of diabetes: what can be done and how much can be prevented? Annu Rev Public Health 2005b, 26:445-467. Review.

19. Heidemann C, Hoffmann K, Spranger J, Klipstein-Grobusch K, Möhlig M, Pfeiffer AF, Boeing $\mathrm{H}$ : A dietary pattern protective against type 2 diabetes in the European Prospective Investigation into Cancer and Nutrition (EPIC)-Potsdam Study cohort. Diabetologia 2005, 48(6):1126-1134.

20. Hoffmann $\mathrm{K}$, Zyriax BC, Boeing $\mathrm{H}$, Windler $\mathrm{E}$ : A dietary pattern derived to explain biomarker variation is strongly associated with the risk of coronary artery disease. Am J Clin Nutr 2004, 80(3):633-640.

21. van Dam RM, Rimm EB, Willett WC, Stampfer MJ, Hu FB: Dietary patterns and risk for type 2 diabetes mellitus in U.S. men. Ann Intern Med 2002a, 136(3):201-209.

22. Liese $A D$, Weis $K E$, Schulz M, Tooze JA: Food intake patterns associated with incident type 2 diabetes: the Insulin Resistance Atherosclerosis Study. Diabetes Care 2009, 32(2):263-268.

23. Fung TT, Schulze M, Manson JE, Willett WC, Hu FB: Dietary patterns, meat intake, and the risk of type 2 diabetes in women. Arch Intern Med 2004 164(20):2235-2240.

24. Montonen J, Knekt P, Härkänen T, Järvinen R, Heliövaara M, Aromaa A Reunanen A: Dietary patterns and the incidence of type 2 diabetes. Am J Epidemiol 2005, 161(3):219-227

25. Hodge AM, English DR, O'Dea K, Giles GG: Dietary patterns and diabetes incidence in the Melbourne Collaborative Cohort Study. Am J Epidemiol 2007, 165(6):603-610.

26. McNaughton SA, Mishra GD, Brunner EJ: Dietary patterns, insulin resistance, and incidence of type 2 diabetes in the Whitehall II Study. Diabetes Care 2008, 31(7):1343-1348. Epub 2008 Apr 4.

27. Hu FB, Malik VS: Sugar-sweetened beverages and risk of obesity and type 2 diabetes: epidemiologic evidence. Physiol Behav 2010, 100(1):47-54.

28. Naja F, Nasreddine L, Itani L, Adra N, Sibai AM, Hwalla N: Association between dietary patterns and the risk of metabolic syndrome among Lebanese adults. Eur J Nutr 2011, [Epub ahead of print].

29. InterAct Consortium, Romaguera D, Guevara M, Norat T, Lagenberg C, Forouhi NG, Sharp S, Slimani N, Schulze MB, Buijsse B, Buckland G, MolinaMontes E, Sánchez MJ, Moreno-Iribas MC, Bendinelli B, Grioni S, Van-der Schouw YT, Arriola L, Beulens JW, Boeing H, Clavel-Chapelon F, Cottet V, Crowe FL, de Lauzon-Guillan B, Franks PW, Gonzalez C, Hallmans G, Kaaks R, Key TJ, Khaw K, Nilsson P, Overvad K, Palla L, Palli D, Panico S, Quirós JR, Rolandsson O, Romieu I, Sacerdote C, Spijkerman AM, Teucher B, Tjonneland A, Tormo MJ, Tumino R, Van-der AD, Feskens EJ, Riboli E, Wareham NJ: Mediterranean diet and type 2 diabetes risk in the European Prospective Investigation into Cancer and Nutrition (EPIC) study: thelnterAct project. Diabetes Care 2011, 34(9):1913-1918. Epub 2011 Jul 25. PubMed PMID: 21788627; PubMed Central PMCID: PMC3161259.

30. de Koning L, Chiuve SE, Fung TT, Willett WC, Rimm EB, Hu FB: Diet-quality scores and the risk of type 2 diabetes in men. Diabetes Care 2011 
34(5):1150-1156. Epub 2011 Apr 4. PubMed PMID: 21464460; PubMed Central PMCID: PMC3114491.

31. Gouveri ET, Tzavara C, Drakopanagiotakis F, Tsaoussoglou M, Marakomichelakis GE, Tountas Y, Diamantopoulos EJ: Mediterranean diet and metabolic syndrome in an urban population: the Athens Study. Nutr Clin Pract 2011, 26(5):598-606.

32. de Lorgeril M: PREDIMED trial: Mediterranean diet may reduce the risk of type 2 diabetes. Evid Based Med 2011, 16(5):152-153. Epub 2011 May 8. PubMed PMID: 21555319.

33. Esmaillzadeh A, Kimiagar M, Mehrabi Y, Azadbakht L, Hu FB, Willett WC: Dietary patterns, insulin resistance, and prevalence of the metabolic syndrome in women. Am J Clin Nutr 2007, 85(3):910-918.

34. Amini M, Esmaillzadeh A, Shafaeizadeh S, Behrooz J, Zare M: Relationship between major dietary patterns and metabolic syndrome among individuals with impaired glucose tolerance. Nutrition 2010, 26(10):986-992.

35. Sibai AM, Zard C, Adra N, Baydoun M, Hwalla N: Variations in nutritional status of elderly men and women according to place of residence. Gerontology 2003, 49(4):215-224.

36. Cohen J: Statistical Power Analysis for the Behavioral Sciences. 2nd edition. Hillsdale, New Jersey: Erlbaum; 1988.

37. Cable A, Nieman DC, Austin M, Hogen E, Utter AC: Validity of leg-to-leg bioelectrical impedance measurement in males. J Sports Med Phys Fitness 2001, 41(3):411-414.

38. Civar S, Aktop A, Tercan E, Ozdol Y, Ozer K: Validity of leg-to-leg bioelectrical impedance measurement in highly active women. J Strength Cond Res 2006, 20(2):359-365.

39. Nasreddine L, Hwalla N, Sibai A, Hamzé M, Parent-Massin D: Food consumption patterns in an adult urban population in Beirut, Lebanon. Public Health Nutr 2006, 9(2):194-203.

40. Pellet PL: Shadarevian Sossy. Food Composition Tables for Use in the Middle East. 2nd edition. Beirut: American University of Beirut; 1970. Library of congress catalogue number:72-131226.

41. Naja F, Nasreddine L, Itani L, Chamieh MC, Adra N, Sibai AM, Hwalla N: Dietary patterns and their association with obesity and sociodemographic factors in a national sample of Lebanese adults. Public Health Nutr 2011, 14(9):1570-1578.

42. Dziuban CD, Shirkey E: When is a correlation matrix appropriate for factor analysis? Psychol Bull 1974, 81(6):358-361.

43. Making Sense of Factor Analysis: The Use of Factor Analysis for Instrument Development in Health Care Research. Calofirnia: Sage publications Inc; 2003.

44. Conway J, Huffcut A: A review and evaluation of exploratory factor analysis practices in organizational research. Org Res Methods 2003, 6(2):147-168.

45. Distefano C, Zhu M, Mindrila D: Understanding and using factor scores: considerations for the applied researcher. Practical Assess Res Eval 2009, 14(20):1-11.

46. Willett WC, Howe GR, Kushi LH: Adjustment for total energy intake in epidemiologic studies. Am J Clin Nutr 1997, 65(Suppl 4):1220S-1228S. discussion 1229S-1231S.

47. Kerver JM, Yang EJ, Bianchi L, Song WO: Dietary patterns associated with risk factors for cardiovascular disease in healthy US adults. Am J Clin Nutr 2003, 78(6):1103-1110.

48. Eilat-Adar S, Mete M, Fretts A, Fabsitz RR, Handeland V, Lee ET, Loria C, Xu J, Yeh J, Howard BV: Dietary patterns and their association with cardiovascular risk factors in a population undergoing lifestyle changes: The Strong Heart study. Nutr Metab Cardiovasc Dis 2012. [Epub ahead of print]

49. Paradis AM, Pérusse L, Vohl MC: Dietary patterns and associated lifestyles in individuals with and without familial history of obesity: a crosssectional study. Int J Behav Nutr Phys Act 2006, 3:38.

50. Esposito K, Kastorini CM, Panagiotakos DB, Giugliano D: Prevention of type 2 diabetes by dietary patterns: a systematic review of prospective studies and meta-analysis. Metab Syndr Relat Disord 2010, 8(6):471-476.

51. Fung TT, Rimm EB, Spiegelman D, Rifai N, Tofler GH, Willett WC, Hu FB: Association between dietary patterns and plasma biomarkers of obesity and cardiovascular disease risk. Am J Clin Nutr 2001, 73(1):61-67.

52. Giovannucci E, Rimm EB, Liu Y, Willett W: Height, predictors of C-peptide and cancer risk in men. Int J Epidemio/ 2004, 33:217-225. doi:0.1093/ije/ dyh020.
53. Malik VS, Fung TT, van Dam RM, Rimm EB, Rosner B, Hu FB: Dietary patterns during adolescence and risk of type 2 diabetes in middle-aged women. Diabetes Care 2012, 35(1):12-18.

54. Sluijs I, Van der Schouw YT, DL VdA, Spijkerman AM, Hu FB, Grobbee DE, Beulens JW: Carbohydrate quantity and quality and risk of type 2 diabetes in the European Prospective Investigation into Cancer and Nutrition-Netherlands (EPIC-NL) study. Am J Clin Nutr 2010, 92(4):905-911.

55. Salmeron J, Manson JE, Stampfer MJ, Colditz GA, Wing AL, Willett WC: Dietary fiber, glycemic load, and risk of non-insulin-dependent diabetes mellitus in women. JAMA 1997, 277:472-477.

56. Hodge AM, English DR, O'Dea K, Giles GG: Glycemic index and dietary fiber and the risk of type 2 diabetes. Diabetes Care 2004, 27:2701-2706.

57. Hu FB, Manson JE, Stampfer MJ, Colditz G, Liu S, Solomon CG, Willett WC: Diet, lifestyle, and the risk of type 2 diabetes mellitus in women. $N$ Engl J Med 2001, 345:790-797.

58. Krishnan S, Rosenberg L, Singer M, Hu FB, Djoussé L, Cupples LA, Palmer JR: Glycemic index, glycemic load, and cereal fiber intake and risk of type 2 diabetes in US black women. Arch Intern Med 2007, 167:2304-2309.

59. Salmerón J, Ascherio A, Rimm EB, Colditz GA, Spiegelman D, Jenkins DJ, Stampfer MJ, Wing AL, Willett WC: Dietary fiber, glycemic load, and risk of NIDDM in men. Diabetes Care 1997, 20:545-550.

60. Schulze MB, Liu S, Rimm EB, Manson JE, Willett WC, Hu FB: Glycemic index, glycemic load, and dietary fiber intake and incidence of type 2 diabetes in younger and middle-aged women. Am J Clin Nutr 2004, 80:348-356.

61. Villegas R, Liu S, Gao YT, Yang G, Li H, Zheng W, Shu XO: Prospective study of dietary carbohydrates, glycemic index, glycemic load, and incidence of type 2 diabetes mellitus in middle-aged Chinese women. Arch Intern Med 2007, 167:2310-2316.

62. Elliott SS, Keim NL, Stern JS, Teff K, Havel PJ: Fructose, weight gain, and the insulin resistance syndrome. Am J Clin Nutr 2002, 76(5):911-922.

63. de Koning L, Malik VS, Rimm EB, Willett WC, Hu FB: Sugar-sweetened and artificially sweetened beverage consumption and risk of type 2 diabetes in men. Am J Clin Nutr 2011, 93(6):1321-1327.

64. Kastorini CM, Panagiotakos DB: Mediterranean diet and diabetes prevention: Myth or fact? World J Diabetes 2010, 1(3):65-67.

65. Dontas AS, Zerefos NS, Panagiotakos DB, Vlachou C, Valis DA: Mediterranean diet and prevention of coronary heart disease in the elderly. Clin Interv Aging 2007, 2:109-115.

66. Moïse MM, Benjamin LM, Doris TM, Dalida KN, Augustin NO: Role of Mediterranean diet, tropical vegetables rich in antioxidants, and sunlight exposure in blindness, cataract and glaucoma among African type 2 diabetics. Int J Ophthalmol 2012, 5(2):231-237.

67. Kastorini CM, Panagiotakos DB: Dietary patterns and prevention of type 2 diabetes: from research to clinical practice; a systematic review. Curr Diabetes Rev 2009, 5(4):221-227.

68. Issa C, Darmon N, Salameh P, Maillot M, Batal M, Lairon D: A Mediterranean diet pattern with low consumption of liquid sweets and refined cereals is negatively associated with adiposity in adults from rural Lebanon. Int $J$ Obes (Lond) 2011, 35(2):251-258.

69. Meyer KA, Kushi LH, Jacobs DR Jr, Folsom AR: Dietary fat and incidence of type 2 diabetes in older lowa women. Diabetes Care 2001, 24(9):1528-1535.

70. Song Y, Manson JE, Buring JE, Liu S: A prospective study of red meat consumption and type 2 diabetes in middle-aged and elderly women: the women's health study. Diabetes Care 2004, 27(9):2108-2115.

71. Brunham LR, Kruit JK, Verchere CB, Hayden MR: Cholesterol in islet dysfunction and type 2 diabetes. J Clin Invest 2008, 118:403e8.

72. Radzevičiene $L$, Ostrauskas R: Egg consumption and the risk of type 2 diabetes mellitus: a case-control study. Public Health Nutr 2012, 15(8):1437-1441.

73. Djoussé L, Gaziano JM, Buring JE, Lee IM: Egg consumption and risk of type 2 diabetes in men and women. Diabetes Care 2009, 32(2):295-300.

74. Meydani M: A Mediterranean-style diet and metabolic syndrome. Nutr Rev 2005, 63(9):312-314.

75. Patel PS, Forouhi NG, Kuijsten A, Schulze MB, Van Woudenbergh GJ, Ardanaz E, Amiano P, Arriola L, Balkau B, Barricarte A, Beulens JW, Boeing H, Buijsse B, Crowe FL, De Lauzon-Guillan B, Fagherazzi G, Franks PW, Gonzalez C, Grioni S, Halkjaer J, Huerta JM, Key TJ, Kühn T, Masala G, Nilsson P Overvad K, Panico S, Quirós JR, Rolandsson O, Sacerdote C, Sánchez MJ, Schmidt EB, Slimani N, Spijkerman AM, Teucher B, Tjonneland A, Tormo MJ, Tumino R, Van-der ADL, Van-der Schouw YT, Sharp SJ, Langenberg C, 
Feskens EJ, Riboli E, Wareham NJ, InterAct Consortium: The prospective association between total and type of fish intake and type 2 diabetes in 8 European countries: EPIC-InterAct Study. Am J Clin Nutr 2012, 95(6):1445-1453.

76. Sato KK, Hayashi T, Harita N, Koh H, Maeda I, Endo G, Nakamura Y, Kambe H, Kiyotaki C: Relationship between drinking patterns and the risk of type 2 diabetes: the Kansai Healthcare Study. J Epidemiol Community Health 2012, 66(6):507-511.

77. Nova E, Baccan GC, Veses A, Zapatera B, Marcos A: Potential health benefits of moderate alcohol consumption: current perspectives in research. Proc Nutr Soc 2012, 71(2):307-315.

78. Hu FB, Rimm E, Smith-Warner SA, Feskanich D, Stampfer MJ, Ascherio A, Sampson L, Willett WC: Reproducibility and validity of dietary patterns assessed with a food-frequency questionnaire. Am J Clin Nutr 1999, 69(2):243-249

79. Willett WC: Invited commentary: comparison of food frequency questionnaires. Am J Epidemio/ 1998, 148(12):1157-1159. discussion 1162-5.

doi:10.1186/1743-7075-9-111

Cite this article as: Naja et al:: Dietary patterns and odds of Type 2

diabetes in Beirut, Lebanon: a case-control study. Nutrition \& Metabolism 2012 9:111.

\section{Submit your next manuscript to BioMed Central and take full advantage of:}

- Convenient online submission

- Thorough peer review

- No space constraints or color figure charges

- Immediate publication on acceptance

- Inclusion in PubMed, CAS, Scopus and Google Scholar

- Research which is freely available for redistribution 